\title{
Towards use of POCUS to evaluate hemodynamics in critically ill neonates: caution before adoption in this population
}

\author{
Patrick J. McNamara ${ }^{1 *}$ (D), Piers Barker ${ }^{2}$, Amish Jain $^{3}$ and Wyman W. Lai ${ }^{4}$
}

Letter to editor regarding "International evidence-based guidelines on Point of Care Ultrasound (POCUS) for critically ill neonates and children issued by the POCUS Working Group of the European Society of Paediatric and Neonatal Intensive Care (ESPNIC)" by Singh et al. Critical Care (2020) 24:65

We read with interest the article by Singh et al. which outlined the role of point-of-care ultrasound (POCUS) in neonatal/pediatric intensive care units [1]. While we commend the authors for their efforts to better standardize indications for POCUS, we have three concerns: First, the presentation of recommendations for POCUS in neonates as evidence-based, rather than as author consensus; second, the inclusion of recommendations for critically ill neonates with older children; and third, the proposal that "these ESPNIC guidelines are developed for use by any neonatologist or paediatric intensivist." Our intent is not to dissuade readers away from the use of POCUS but to restore balance between the desired recommendations and strength of available evidence and to offer additional suggestions.

(i) It is notable that only 2 recommendations achieve Quality of Evidence of A [(i)POCUS should not be used as a screen to diagnose congenital heart defects; (ii) assessment of ductus arteriosus patency], 4 reach level B (assessment of pulmo-

This comment refers to the article available at https://doi.org/10.1186/s1305 4-020-2787-9.

*Correspondence: patrick-mcnamara@uiowa.edu

${ }^{1}$ Division of Neonatology, University of lowa, 200 Hawkins Drive, lowa City, IA 52242, USA

Full list of author information is available at the end of the article nary artery pressures or pericardial fluid), while the remainder is classed as weak evidence. Surprisingly, the authors present strong agreement for all recommendations which creates an impression of greater validation than the evidence supports.

(ii) We believe the approach may inadvertently equate neonates to "small children." Appraisal of cardiovascular physiology in critically ill neonates is challenging due to the complexity of the transitional circulation, unique interplay with neonatal disease and developmental variability of cardiovascular drugs. In addition, the reliability of subjective assessment of heart function or chamber size is questionable. We strongly believe that recommendations for POCUS in neonates be developed separately.

(iii) While availability of portable ultrasound machines has expanded, permitting the field to advance, related guidelines are incomplete. Published guidelines articulate the need for a well-defined training structure and guidelines for clinical practice [2-4]. Successful establishment of hemodynamic programs is attributed to the comprehensive nature of imaging protocols, exposure to higher case volume and organizational governance. The rates of attainment of imaging and interpretative competence are not congruent, and individual learning is also influenced by the complexity of pathophysiology and disease.

A recent survey indicated that the establishment of hemodynamic programs is a high priority for neonatology leaders, as there is recognition that

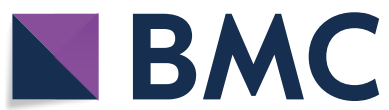

(c) The Author(s) 2021. Open Access This article is licensed under a Creative Commons Attribution 4.0 International License, which permits use, sharing, adaptation, distribution and reproduction in any medium or format, as long as you give appropriate credit to the original author(s) and the source, provide a link to the Creative Commons licence, and indicate if changes were made. The images or other third party material in this article are included in the article's Creative Commons licence, unless indicated otherwise in a credit line to the material. If material is not included in the article's Creative Commons licence and your intended use is not permitted by statutory regulation or exceeds the permitted use, you will need to obtain permission directly from the copyright holder. To view a copy of this licence, visit http://creativecommons.org/licenses/by/4.0/. The Creative Commons Public Domain Dedication waiver (http://creativeco mmons.org/publicdomain/zero/1.0/) applies to the data made available in this article, unless otherwise stated in a credit line to the data. 
meticulous hemodynamic data are essential to optimize care [5]. At this juncture, leaders in POCUS and Neonatal Hemodynamics should strategize the scope of training and clinical application of cardiac POCUS to maximize the potential of this modality to improve patient care (Fig. 1).

\section{Authors' response}

Y. Singh, C. Tissot, M. V. Fraga, N. Yousef, R. G. Cortes, J. Lopez, J. Sanchez-de-Toledo, J. Brierley, J. M. Colunga, D. Raffaj, E. DaCruz, P. Durand, P. Kenderessy, H. J. Lang, A. Nishisaki, M. C. Kneyber, P. Tissieres, T. W. Conlon, D. DeLuca

We thank the Editor for giving the opportunity to address the concerns and comments by McNamara et al.

First, we agree that a comprehensive hemodynamic evaluation involves echocardiographic assessment using many parameters including precise objective measurements [6]. Our published guidelines recommend the use of cardiac POCUS to assess individual components within a patient's hemodynamic profile [7]. It refers to a basic, time-sensitive and focused echocardiographic assessment. For example, one of the indications includes "POCUS can be used for checking the patency of ductus arteriosus" which is only one consideration within the complex hemodynamic and physiologic evaluation of patent ductus arteriosus [8, 9]. Development of hemodynamic programs integrating subjective and objective echocardiographic measures within robust clinical experiences specific to the practice of neonatology is indeed a desired goal. Yet many neonatologists can answer fundamental, frequently asked, clinically relevant and lifesaving questions with basic POCUS training. Defining POCUS applications for the broader neonatal community and distinguishing applications for complete hemodynamic program development for neonatal specialists are important ongoing work, as we further discuss below.

Second, we would like to emphasize that these recommendations followed strict methodology consistent with other ESPNIC guidelines and are evidence-based, not expert-consensus guidelines [10]. We agree with McNamara et al. that some recommendations reached to a strong agreement despite "weak evidence grade." Workgroups purposefully assessed recommendations beyond evidence within the literature since these data frequently "miss" the clinical context that can be provided by experts within a field. Many ultrasound indications have already become standard of care in daily clinical practice despite a prior absence of guidelines. For example, even in absence of high-grade evidence, any expert would agree that bedside ultrasound is the best and quickest imaging modality for the detection of pericardial effusion or to guide pericardiocentesis. Further, we can wait for the literature to demonstrate superiority of ultrasound-guided vascular access across all neonatal applications or accept that visualization of a needle tip as it enters a vessel is safer than nonvisualization, and that the drive for "quality of evidence $A$ " may ultimately impose unnecessary harm. This is similar to the use of echocardiography for diagnosing

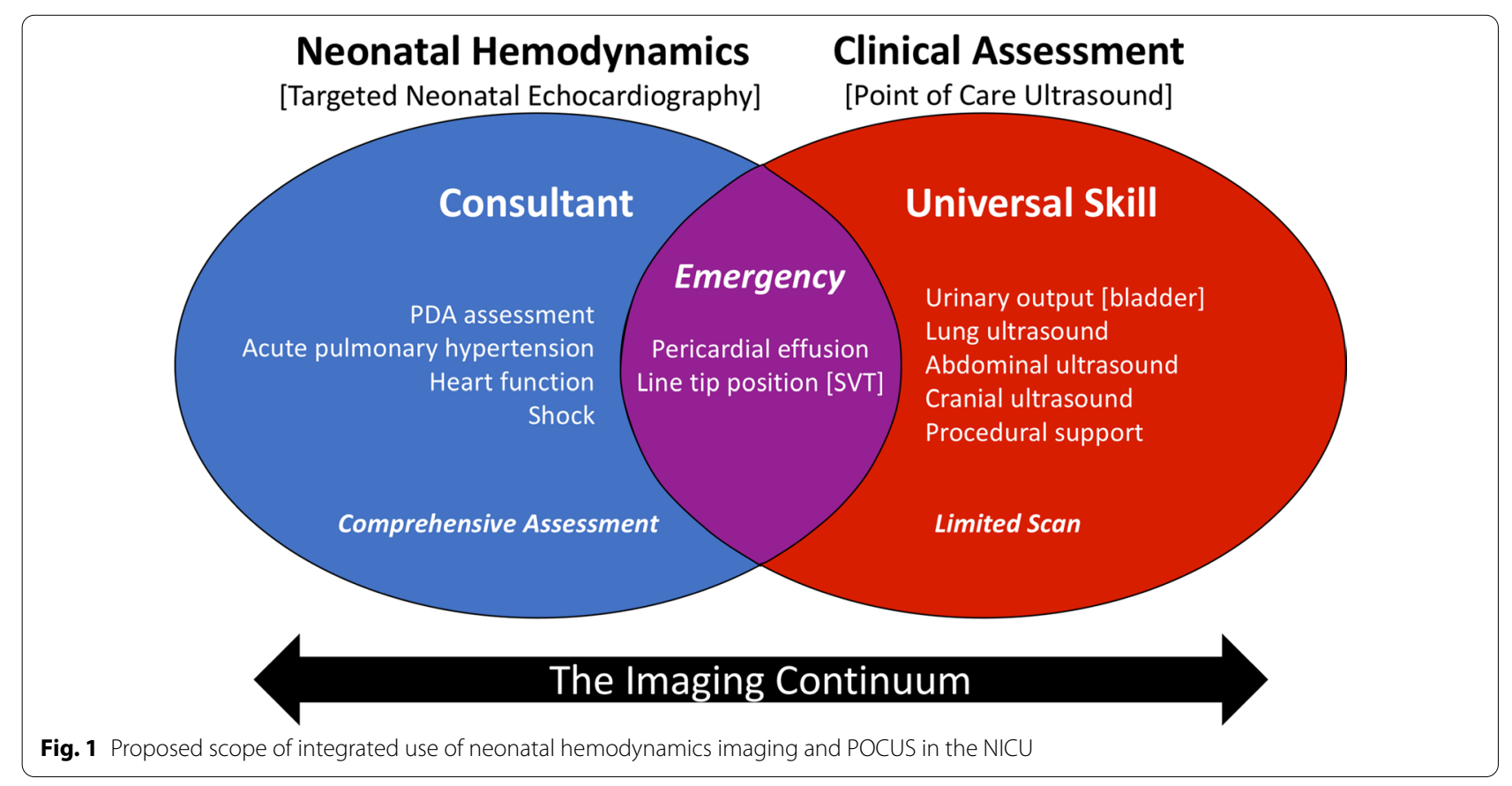


congenital heart defects (CHD) by a pediatric cardiologist; there is no disagreement that echocardiography is the investigation of choice to diagnose CHD despite the lack of published high-grade evidence.

Third, we agree with McNamara et al. that these guidelines are not for use by any neonatologist. Evidence-based guidelines have been prepared to define the clinical indications where POCUS can be used. The authors would agree that defining specific indications helps to prevent inadvertent use of POCUS in situations where its role is less clear or in settings where an adequate standard of care is lacking. For example, unlike neonatologist performed echocardiography (NPE) cardiac POCUS should not be used as a screening tool for congenital heart defects [7]. We believe that POCUS should be used for specific clinical indications and by appropriately trained clinicians [7]. Furthermore, we agree that paths translating training to competence at the bedside are necessary, and this work is ongoing within the POCUS community. Finally, POCUS is not an alternative to NPE or specialist echocardiography [7], which involves comprehensive training in hemodynamic evaluation and protocol-based assessments.

The purpose of guidelines is to guide the implementation of a tool within identified situations or settings where the care of a patient may be improved. The practice of neonatal critical care may be very different in different countries and regions, whether developing countries, American or European NICUs. We believe that with appropriate training, cardiac POCUS can be a useful tool for neonatal and pediatric intensivists to improve standards of care in critically ill children of all ages. Specific to Europe, a relevant proportion of units are mixed pediatric/neonatal critical care, and clinicians are trained to care for both types of patients.

There is no doubt that pathophysiologies amenable to POCUS applications bridge the neonatal-pediatric divide. We certainly agree that neonates are not small children, but are there more differences in physiology and physiopathology more than similarities? Many examples point to convergence rather than divergence of applications, demonstrated by the extension of adult lung ultrasound principles in the assessment of neonatal diseases.

We are in full agreement that cardiac POCUS, neonatologist performed targeted echocardiography and comprehensive echocardiography by the pediatric cardiologist are 'the continuum' of cardiac imaging. Compared to NPE, cardiac POCUS is designed for specific indications only, involves limited imaging and hence, relatively shorter training-allowing utilization of this important skill by more acute physicians in their clinical practice. The neonatal and pediatric intensivists performing both cardiac POCUS and NPE should work in close collaboration with the pediatric cardiologists as recommended in the guidelines (1-4). The consensus reached by the authors in developing our guidelines demonstrate the potential of this important collaboration, which we trust will enhance the care of critically ill newborns and children in the ICU environment. Working together they can share good practice and learn from each other while delivering the best possible care to their patients.

\section{Acknowledgements \\ Not applicable}

\section{Authors' contributions}

PJM, PB, AJ and WWL conceived of the concept and planned the content. PJM wrote the first draft. All authors read and approved the final manuscript.

Funding

No funding was received for the preparation of this letter.

Availability of data and materials

Not applicable.

Ethics approval and consent to participate

Not applicable.

Consent for publication

Not applicable.

Competing interests

The authors declare that they have no competing interests.

\section{Author details}

${ }^{1}$ Division of Neonatology, University of lowa, 200 Hawkins Drive, lowa City, IA 52242, USA. ${ }^{2}$ Duke University Medical Center, Durham, NC, USA. ${ }^{3}$ University of Toronto, Toronto, Canada. ${ }^{4}$ University of California, Irvinelrvine, CA, USA.

Received: 25 October 2020 Accepted: 18 November 2020 Published online: 03 March 2021

\section{References}

1. Singh $Y$, Tissot C, Fraga MV, Yousef N, Cortes RG, Lopez J, Sanchez-deToledo J, Brierley J, Colunga JM, Raffaj D, Da Cruz E, Durand P, Kenderessy P, Lang HJ, Nishisaki A, Kneyber MC, Tissieres P, Conlon TW, De Luca D. International evidence-based guidelines on Point of Care Ultrasound (POCUS) for critically ill neonates and children issued by the POCUS Working Group of the European Society of Paediatric and Neonatal Intensive Care (ESPNIC). Crit Care. 2020;24:65.

2. Mertens L, Seri I, Marek J, Arlettaz R, Barker P, McNamara P, Moon-Grady AJ, Coon PD, Noori S, Simpson J, Lai WW. Targeted Neonatal Echocardiography in the Neonatal Intensive Care Unit: practice guidelines and recommendations for training. Writing Group of the American Society of Echocardiography (ASE) in collaboration with the European Association of Echocardiography (EAE) and the Association for European Pediatric Cardiologists (AEPC). J Am Soc Echocardiogr. 2011;24:1057-78.

3. de Boode WP, Singh Y, Gupta S, Austin T, Bohlin K, Dempsey E, Groves A, Eriksen BH, van Laere D, Molnar Z, Nestaas E, Rogerson S, Schubert $U$, Tissot C, van der Lee R, van Overmeire B, El-Khuffash A. Recommendations for neonatologist performed echocardiography in Europe: Consensus Statement endorsed by European Society for Paediatric Research (ESPR) and European Society for Neonatology (ESN). Pediatr Res. 2016:80:465-71. 
4. Singh Y, Gupta S, Groves AM, Gandhi A, Thomson J, Qureshi S, Simpson JM. Expert consensus statement 'Neonatologist-performed Echocardiography (NoPE)'-training and accreditation in UK. Eur J Pediatr. 2016;175:281-7.

5. Giesinger RE, Stanford AH, Rios DR, Bhombal S, Fraga MV, Levy VY, McNamara PJ. Targeted neonatal echocardiography in the United States of America: the contemporary perspective and challenges to implementation. Pediatr Res. 2019;85:919-21.

6. Singh Y. Echocardiographic evaluation of hemodynamics in neonates and children. Front Pediatr. 2017;5:201.

7. Singh Y, Tissot C, Fraga MV, Yousef N, Cortes RG, Lopez J, et al. International evidence-based guidelines on Point of Care Ultrasound (POCUS) for critically ill neonates and children issued by the POCUS Working Group of the European Society of Paediatric and Neonatal Intensive Care (ESPNIC). Crit Care. 2020;24:65.

8. Hébert A, Lavoie PM, Giesinger RE, Ting JY, Finan E, Singh Y, et al. Evolution of training guidelines for echocardiography performed by the neonatologist: toward hemodynamic consultation. J Am Soc Echocardiogr. 2019;32(6):785-90.

9. Singh Y, Fraisse A, Erdeve O, Atasay B. Echocardiographic diagnosis and hemodynamic evaluation of patent ductus arteriosus in extremely low gestational age newborn (ELGAN) infants. Front Pediatr. 2020; 8:573627. https://doi.org/10.3389/fped.2020.573627.

10. Kneyber MCJ, de Luca D, Calderini E, Jarreau P-H, Javouhey E, LopezHerce J, et al. Recommendations for mechanical ventilation of critically ill children from the Paediatric Mechanical Ventilation Consensus Conference (PEMVECC). Intensive Care Med. 2017;43:1764-80.

\section{Publisher's Note}

Springer Nature remains neutral with regard to jurisdictional claims in published maps and institutional affiliations.
Ready to submit your research? Choose BMC and benefit from:

- fast, convenient online submission

- thorough peer review by experienced researchers in your field

- rapid publication on acceptance

- support for research data, including large and complex data types

- gold Open Access which fosters wider collaboration and increased citations

- maximum visibility for your research: over $100 \mathrm{M}$ website views per year

At BMC, research is always in progress.

Learn more biomedcentral.com/submissions 